\title{
The anti-inflammation effect of strontium ranelate on rat chondrocytes with or without IL-1 $\beta$ in vitro
}

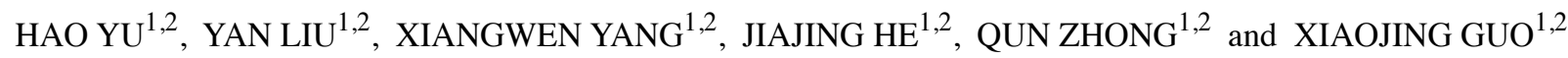 \\ ${ }^{1}$ Department of Prosthodontics, Shanghai Stomatological Hospital; ${ }^{2}$ Shanghai Key Laboratory of \\ Craniomaxillofacial Development and Diseases, Fudan University, Huangpu, Shanghai 200001, P.R. China
}

Received August 27, 2021; Accepted December 10, 2021

DOI: 10.3892/etm.2022.11131

\begin{abstract}
Temporomandibular joint osteoarthritis (TMJ-OA) is a common disease with a high level of inflammation in the joint micro-environment and cartilage degradation. Anti-inflammation and cartilage regeneration are the key therapies for TMJ-OA, but currently, there are no novel medicines or treatments that can control its pathogenic progression. Strontium ranelate ( $\mathrm{SrR}$ ) is an anti-osteoporosis drug and is now considered a promising anti-OA drug, but the anti-inflammatory effect of SrR remains to be elucidated. In the present study, the anti-inflammatory effect of SrR in a normal or high IL- $1 \beta$ environment was observed. Cell viability under the treatment of SrR was tested using Cell Counting Kit-8. Toluidine blue staining, immunofluorescence staining, hydroxyproline assay, PCR assay and western blotting were used to detect the expression of collagen ( $\mathrm{Col}) \mathrm{II}$, proteoglycans (PG) and aggrecan as a reflection of extracellular matrix synthesis and MMP-9,13 hydroxyproline was used as an inflammation indicator. IL-1 $\beta$ of $10 \mathrm{ng} / \mathrm{ml}$ was added to the culture medium as inflammation environment and the tests of those biomarkers were done again. Then, the changes in $\beta$-catenin were also studied by immunofluorescence staining, PCR assay and western blotting to explore the possible involvement of the $\mathrm{Wnt} / \beta$-catenin pathway. The results showed a significant inhibition of MMP-9, MMP-13, $\beta$-catenin and promotion of Col-II, PG and aggrecan in normal chondrocytes. The presence of IL-1 $\beta$ markedly upregulated the expression of MMP-9, MMP-13 and $\beta$-catenin while suppressing Col-II and PG and SrR partially reversed this trend. In conclusion, SrR decreased MMPs but promoted Col-II, aggrecan and PG synthesis in rat chondrocytes with or without the presence of IL-1 $\beta$ and SrR attenuated the IL-1 $\beta$-induced increase in $\beta$-catenin, thus reducing the inflammatory reaction.
\end{abstract}

Correspondenceto:DrXiaojing Guo,DepartmentofProsthodontics, Shanghai Stomatological Hospital, 356 East Beijing Road, Huangpu, Shanghai 200001, P.R. China

E-mail: guo_xiaojing@fudan.edu.cn

Key words: strontium ranelate, chondrocytes, anti-inflammation, IL- $1 \beta, \beta$-catenin

\section{Introduction}

Temporomandibular disease (TMD) is one of the most common dental diseases and is characterized by temporomandibular joint (TMJ) pain, snapping and difficulty in opening the mouth, which seriously affect quality of life. There are several causes of TMJ inflammation, including abnormal biomechanical stress, injury, or systematic disease, such as rheumatoid arthritis, which result in TMD (1). TM joint osteoarthritis (TMJ-OA) is one of the most common cases of TMD and it is typically characterized by cartilage degradation and is very difficult to cure. At present, the main pathological changes of TMJ-OA include an increase in inflammatory factors, chondrocyte degeneration and apoptosis, matrix collagen decomposition and abnormal remodeling of subchondral bone (2). Chondrocytes are the only cell component in cartilage tissue (3). When the balance of the joint microenvironment is disturbed by factors such as abnormal stress, ageing and genetic factors, inflammatory factors such as IL-1 $\beta$, TNF- $\alpha$ and nitric oxide (NO) increase (4), chondrocytes become irritated and secrete excessive MMPs, e.g. MMP-13, aggrecanases (ADAMTS-4, -5), nitric oxide synthase (iNOS) and cyclooxygenase-2 (COX-2), which leads to extracellular matrix (ECM) decomposition $(5,6)$. Moreover, chondrocytes in an inflammatory state also secrete various inflammatory factors, such as IL- $1 \beta$, TNF- $\alpha$, IL-6 and IL-8, further leading to the aggravation of inflammation in the joint microenvironment (7). This vicious cycle of inflammation will eventually lead to cartilage destruction and the development of OA (8).

A previous study emphasizes that the altered joint mechanics that cause OA are addressed in first-line therapy, which stresses the rehabilitation of normal biomechanical and non-inflammation microenvironments (9). Unfortunately, there are currently no pharmacological treatments or effective interventions that can alter the joint mechanics to halt or reverse the progression of OA in the long term. As OA involves a number of pathways and risk factors, personalized therapy is the ultimate goal, which requires different targeted disease-modifying OA drugs (DMOADs) for suitable therapeutic options (10). The pool of DMOADs is always in need of growth.

Strontium ranelate (SrR) is an anti-osteoporosis drug that has the dual effect of promoting bone formation and inhibiting bone resorption and has been recently considered a possible 
DMOAD (11). As a promising DMOAD, SrR has some special advantages. First, SrR has a good tolerability and safety profile and is well tolerated by the majority of patients in long-term treatment (12). Second, SrR can modify subchondral bone turnover, thus indirectly modifying chondrocytes in cartilage via factors released from bone $(13,14)$. Third, in our previous study, it was shown that SrR has a chondrogenic induction effect on bone mesenchymal stem cells (BMSCs) that promotes cartilage regeneration and suppresses cartilage degradation by inhibiting the formation of MMPs in vitro and in vivo (15). However, the anti-inflammatory effect of SrR has not yet been fully elucidated.

Evidence of IL-1 $\beta$ in progressing OA is well established and is also an essential factor when simulating the OA environment in vitro (6). Increased IL-1 $\beta$ leads to abnormal regulation of MMPs, induces chondrocytes to produce large amounts of NO, causes abnormal mitochondrial function and leads to chondrocyte apoptosis and promotes chondrocytes to produce PEG-2 and other inflammatory mediators, leading to degradation of PG and collagen (16). However, few studies of the anti-inflammation effect of SrR have been conducted. Alves et al (17) published research on antinociceptive effects of SrR; that orally taken SrR could reduce TNF- $\alpha$ levels in periarticular tissues and trigeminal ganglion, but did not decrease IL-1 $\beta$ expression, nor inhibit HO-1 pathway. As the gastrointestinal barrier would block ranelate acid outside the blood serum, it was not possible to predict the same result in an in vitro study. The in vitro study of Henrotin et al (18) showed that SrR had a significant inhibitory effect on MMPs and simulated PG synthesis even under an inflammatory environment, but that study did not advance mechanistic investigations. Above all, whether SrR could suppress the inflammation level of IL-1 $\beta$, MMPs and stabilize ECM proteins directly on chondrocytes and the underlying mechanism remain to be elucidated.

The treatment of TMJ-OA involves the regeneration of cartilage, which, using the method of tissue engineering, requires plenty of cells. The chondrocytes from healthy TMJ are limited and it is reasonable to obtain chondrocytes from other site of cartilage (19). The present study employed the chondrocytes from rat femurs and aimed to investigate whether SrR exerted a protective effect by reducing rat chondrocyte inflammation caused by IL-1 $\beta$. To explore its effect on chondrocyte cell viability, ECM matrix synthesis, the expression of cartilage-forming or inflammation genes and proteins and the involvement of the molecular mechanism of SrR in Wnt/ $\beta$-catenin signaling pathways was examined.

\section{Materials and methods}

Isolation and culture of rat chondrocytes. Rat chondrocytes cells were isolated from Sprague-Dawley (SD) rats. Briefly, 12 male SD rats of 4-6 weeks (weight 100-120 g) were purchased from Vital River Laboratories. Rats were sacrificed on receipt by sodium pentobarbital at a dosage of $150 \mathrm{mg} / \mathrm{kg}$ intraperitoneal injection and followed with strict disinfection, the cartilage tissue on the top of the metaphysis of the knee side was cut with a knife and washed twice with PBS and twice with Hanks' Balanced Salt Solution (HBSS). After washing, cartilage tissues were cut into small pieces and incubated in HBSS (containing $\mathrm{Ca}^{2+}$ and $\mathrm{Mg}^{2+}$ ) with $200 \mathrm{U} / \mathrm{ml}$ type II collagenase (Gibco; Thermo Fisher Scientific, Inc.; cat. no. $17101-015)$ at $37^{\circ} \mathrm{C}$ and $5 \% \mathrm{CO}_{2}$ for $12 \mathrm{~h}$. The cells were centrifuged at $300 \mathrm{x}$ g for $5 \mathrm{~min}$ (room temperature), resuspended in high-glucose DMEM (Gibco; Thermo Fisher Scientific, Inc.) with 10\% FBS (Gibco; Thermo Fisher Scientific, Inc.) and then subjected to routine cell culture procedures. Chondrocytes with 3-5 passages were used for the present study.

The present study was performed strictly in accordance with the recommendations in the Guide for the Care and Use of Laboratory Animals of the National Institutes of Health (20). All experiments were approved by the Animal Research Committee of the Shanghai Stomatological Hospital and Shanghai Research Center of Model Animal Organization (IACUC no. 2020-0010-06).

Cell treatment with $S r R$ and $I L-1 \beta$. Chondrocytes were treated with different concentrations of SrR and induced by IL-1 $\beta$ to simulate inflammation. As described in our previous study $(15,21), 51.35 \mathrm{mg}$ of SrR (MilliporeSigma) was dissolved in $50 \mathrm{ml}$ of culture medium to obtain a maximum soluble concentration of $2.0 \mathrm{mmol} / \mathrm{l}$. Then, the samples were diluted to different concentrations of 1.0, 0.5, 0.25 and $0.125 \mathrm{mmol} / \mathrm{l}$.

IL-1 $\beta$-treated chondrocytes or cartilage tissues have been widely adopted as in vitro models to study OA (6). The recombinant rat IL-1 $\beta$ protein was purchased from BioVision, Inc. (cat. no. 4130-10) and a final concentration of $10 \mathrm{ng} / \mathrm{ml}$ was used for the present study.

Chondrocytes cell proliferation assay. The proliferation of chondrocytes under different concentrations of SrR was detected by CCK-8 assay. Briefly, the chondrocytes were inoculated in 96-well plates (initial cell density of $3 \times 10^{3}$ cells/well) and treated with $\operatorname{SrR}(0,0.125,0.25,0.5,1.0$ and $2.0 \mathrm{mmol} / \mathrm{l})$ for $1,3,5$ and 7 days. CCK-8 (10 $\mu \mathrm{l})$ solution in $5 \% \mathrm{CO}_{2}$ was added to each plate and incubated at $37^{\circ} \mathrm{C}$ for $1 \mathrm{~h}$ under dark conditions. Optical density (OD) values reflecting cell viability were measured by a microplate reader (BioTek Instruments, Inc.; ELX800) at a wavelength of $450 \mathrm{~nm}$.

Toluidine blue staining. The chondrocytes were seeded on 24-well plates at an initial density of $1 \times 10^{4}$ cells/well with DMEM added with SrR at $0.125,0.25$ and $0.5 \mathrm{mmol} / 1$ for 14 days induction, while initial cell density of $1 \times 10^{5}$ cells/well for the cultural medium with IL-1 and $0.25 \mathrm{mmol} / 1 \mathrm{SrR}$, and for 3 days, at $37^{\circ} \mathrm{C}$. Then, the chondrocytes were fixed with $4 \%$ paraformaldehyde at $4^{\circ} \mathrm{C}$ for $30 \mathrm{~min}$ and stained with a toluidine blue solution at room temperature for $30 \mathrm{~min}$ (Beijing Solarbio Science \& Technology Co., Ltd.) following 3 or 14 days of induction. Images were captured with an inverted light microscope (Leica DMI 3000B; Leica Microsystems $\mathrm{GmbH})$ at x200 magnification.

Hydroxyproline (Hyp) assay. An Hyp assay revealed the degradation condition of collagen. Hyp is the characteristic amino acid that is composed of collagen and does not exist in other human tissues (22). A hydroxyproline test kit (Abcam; cat. no. ab222941) was used in accordance with the manufacturer's instructions. Cell culture supernatant, $\mathrm{ddH}_{2} \mathrm{O}$ and 
Table I. Primer sequences used for the rat chondrocytes.

\begin{tabular}{llc}
\hline Gene & \multicolumn{1}{c}{ Forward } & Reverse \\
\hline Col-II & ATCGCCACGGTCCTACAATG & GGCCCTAATTTTCGGGCATC \\
Aggrecan & CAAGTCCCTGACAGACACCC & GTCCACCCCTCCTCACATTG \\
MMP-9 & GATCCCCAGAGCGTTACTCG & GTTGTGGAAACTCACACGCC \\
MMP-13 & TGCTGCATACGAGCATCCAT & TGTCCTCAAAGTGAACCGCA \\
$\beta$-catenin & ACTCCAGGAATGAAGGCGTG & GAACTGGTCAGCTCAACCGA \\
GAPDH & AGTGCCAGCCTCGTCTCATA & GATGGTGATGGGTTTCCCGT
\end{tabular}

standard protein samples were prepared and an equal volume of $\mathrm{NaOH}$ was added, evaporated, cooled and neutralized with an equal amount of $\mathrm{HCl}$. Then, the supernatant was centrifuged at $10,000 \mathrm{x}$ g for $5 \mathrm{~min}$ (room temperature) and collected into a new tube. An oxidation reagent was added and the solution was incubated at room temperature for $20 \mathrm{~min}$. A developer was added and the solution was incubated at $37^{\circ} \mathrm{C}$ for $5 \mathrm{~min}$. DMAB concentrate was added and the solution was incubated at $65^{\circ} \mathrm{C}$ for $45 \mathrm{~min}$. The $\mathrm{OD}$ value of each group was measured by microplate reader at $560 \mathrm{~nm}$ wavelength. The test was repeated for three times and the hydroxyproline concentration was calculated by the standard curve method.

Immunofluorescence staining assay. The chondrocytes were cultured in DMEM with or without IL-1 and SrR at $0.125,0.25$ and $0.5 \mathrm{mmol} / 1$ for 14 days at $37^{\circ} \mathrm{C}$. First, the cells were rinsed with PBS and fixed at $4^{\circ} \mathrm{C}$ with $4 \%$ paraformaldehyde for $15 \mathrm{~min}$. Second, the cells were treated with PBST for $10 \mathrm{~min}$ under room temperature for permeability and rinsed with PBS several times (5 min; room temperature). Then, non-specific interactions were blocked with donkey serum and incubated with primary antibodies against $\beta$-catenin (Abcam; cat. no. ab16051), collagen (Col)-II (ProteinTech Group, Inc.; cat. no. 15943-1-AP) and MMP-13 (Novus Biologicals, LLC; cat. no. NBP2-17310). Cyanine 3-conjugated donkey anti-rabbit IgG (cat. no. GB21403; Wuhan Servicebio Technology Co., Ltd.) was used as a secondary antibody and nuclei were stained with DAPI (MilliporeSigma; cat. no. D9642). Images were captured by a fluorescence microscope at x200 magnification.

Reverse transcription-quantitative $(R T-q) P C R$. The chondrocytes were cultured in 6-well plates at a density of $5 \times 10^{4}$ cells/well with DMEM added with SrR at 0.125, 0.25 and $0.5 \mathrm{mmol} / 1$ for 14 days induction and total RNA extracted at days 1,7 and 14 . With initial cell density of $5 \times 10^{5}$ cells/well for the cultural medium with IL-1 and $0.25 \mathrm{mmol} / 1 \mathrm{SrR}$ the total RNA was extracted at days 1,2 and 3 using TRIzol ${ }^{\circledR}$ reagent (Thermo Fisher Scientific, Inc.) according to the manufacturer's protocol. RNA purity and quantification were tested by NanoDrop One Microvolume Spectrophotometer (Thermo Fisher Scientific, Inc.). The RNA was used as a template for cDNA reverse by Tiangen FastKing cDNA Dispelling RT SuperMix (cat. no. KR118; Tiangen Biotech Co., Ltd.) following the manufacturer's instructions. The resultant cDNA (100 ng) was amplified in a $20 \mu \mathrm{l}$ reaction system containing
$10 \mu 1$ 2X SuperReal PreMix Plus (cat. no. FP205; KR118), $1.2 \mu \mathrm{l}$ forward/reverse primer, $2 \mu \mathrm{l} \mathrm{cDNA}$ template and $6.8 \mu \mathrm{l}$ RNase-free $\mathrm{dd}_{2} \mathrm{O}$. The PCR cycling conditions were as follow: Initial denaturation at $95^{\circ} \mathrm{C}$ for $15 \mathrm{~min}$, followed by 40 cycles of denaturation at $95^{\circ} \mathrm{C}$ for $10 \mathrm{sec}$, annealing at $60^{\circ} \mathrm{C}$ for $20 \mathrm{sec}$ and extension at $72^{\circ} \mathrm{C}$ for $20 \mathrm{sec}$. All experiments were repeated three times and the relative fold-change of gene expression ( $2^{-\Delta \Delta \mathrm{Cq}}$ method) was calculated by the $\mathrm{Ct}$ value (23) (LightCycler 96 PCR system; Roche Diagnostics GmbH). The primer sequences are in Table I. All tests were performed in triplicate.

Western blotting assay. The chondrocytes were cultured in 6 -well plates at a density of $5 \times 10^{4}$ cells/well and treated with or without $\mathrm{SrR}$ at $0.125,0.25$ and $0.5 \mathrm{mmol} / \mathrm{l}$ for 14 days, an initial density of $5 \times 10^{5}$ cells/well treated with or without IL-1 and $0.25 \mathrm{mmol} / \mathrm{l} \mathrm{SrR}$ for 3 days at $37^{\circ} \mathrm{C}$. After rinsing with PBS several times, total proteins were collected by RIPA buffer (Beyotime Institute of Biotechnology) on ice and measured by a BCA protein assay kit (Beyotime Institute of Biotechnology). Equivalent amounts of protein $(20 \mu \mathrm{g} /$ lane $)$ were transferred to PCDF membranes on $12 \%$ SDS-PAGE gels. Following blocking with $5 \%$ skimmed milk at room temperature for $1 \mathrm{~h}$, the membrane was exposed to primary antibodies at $4^{\circ} \mathrm{C}$ overnight, including Col-II (1:500; cat. no. 28459-1-AP; ProteinTech Group, Inc.), aggrecan (1:500; cat. no. 13880-1; ProteinTech Group, Inc.), $\beta$-catenin (1:1,000; cat. no. ab16051; Abcam), MMP-9 (1:500; cat. no. 10375-2; ProteinTech Group, Inc.), MMP-13 (1:500; cat. no. Nbp2-17310; Novus Biologicals) and $\beta$-actin (1:1,000; cat. no. 4970; Cell Signaling Technology, Inc.). Then, PBST was washed and incubated with HRP-labelled goat anti-rabbit IgG (1:1,000; cat. no. A0208; Beyotime Institute of Biotechnology) or HRP-labelled goat anti-mouse IgG (1:1,000; cat. no. A0216; Beyotime Institute of Biotechnology) at room temperature for $2 \mathrm{~h}$. The membrane was thoroughly cleaned and visualized using ECL reagents (Pierce; Thermo Fisher Scientific, Inc.). The bands were imaged and measured by the Quantity One Analysis system (version 4.6.6.; Bio-Rad Laboratories, Inc.).

Statistical analysis. The results are shown as the mean \pm standard deviation of three repeated experiments and were analyzed by SPSS 26.0 software (IBM Corp.). One-way analysis of variance (ANOVA) with a subsequent post hoc Tukey's test was used to determine the statistical significance of the differences among groups. $\mathrm{P}<0.05$ was considered to indicate a statistically significant difference. 


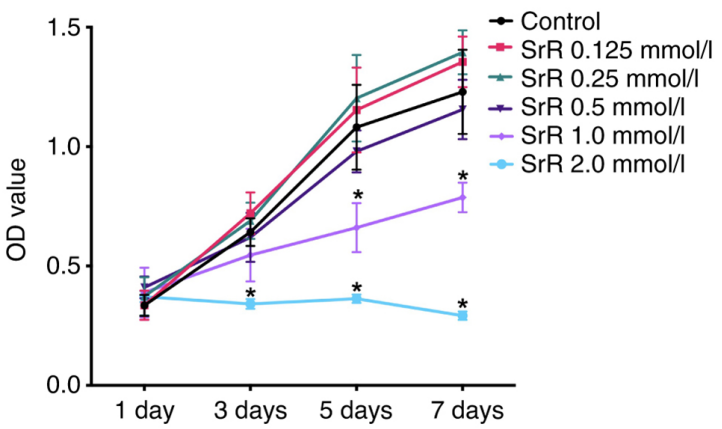

Figure 1. Effect of SrR on rat chondrocytes viability. The OD values of every group at day 1,3,5 and 7 are presented and no significant differences were observed among the control, SrR $0.125,0.25$ and $0.5 \mathrm{mmol} / 1$ groups, while the OD values of the SrR $2.0 \mathrm{mmol} / \mathrm{l}$ at day 3,5 and 7 and $\mathrm{SrR} 1.0 \mathrm{mmol} / 1$ at day 5 and 7 groups were significantly lower compared with the control $\left({ }^{*} \mathrm{P}<0.05\right)$. SrR, strontium ranelate; OD, optical density; d, day.

\section{Results}

Effects of SrR on chondrocyte viability. Cells isolated from rat femur cartilage were positively stained with Col-II and aggrecan, but negatively with Col-I and 11-fibrau, which made them identify as chondrocytes (Fig. S1).

The influence of SrR on rat chondrocyte viability was tested by a CCK-8 assay. As illustrated in Fig. 1, SrR at low concentrations, including $0.125,0.25$ and $0.5 \mathrm{mmol} / 1$, did not suppress cell viability at days 1,3,5 and 7 and no significant differences were observed between the control group and these groups. High concentrations of $\mathrm{SrR}(1.0$ and $2.0 \mathrm{mmol} / \mathrm{l})$ significantly inhibited cell proliferation. The results indicated that the application of SrR on chondrocytes was safer when the concentration is $<0.5 \mathrm{mmol} / \mathrm{l}$ (Fig. 1).

Effects of SrR on chondrocyte PG synthesis, hydroxyproline (Hyp) concentration and gene expression. The chondrocytes were treated with $0,0.125,0.25$ and $0.50 \mathrm{mmol} / 1 \mathrm{SrR}$ for 14 days and toluidine blue staining revealed the PG content, which reflects the normal synthesis function of chondrocytes. The level of Hyp in extracellular fluid can reversely reflect the degradation of collagen caused by inflammation or other reasons. PCR tests were performed on days 1, 7 and 14 to determine the gene expression of marker genes.

As shown in Fig. 2A, every SrR group had a darker stain than that of the control group and the 0.25 and $0.50 \mathrm{mmol} / 1 \mathrm{SrR}$ groups were more intense than the $0.125 \mathrm{mmol} / 1$ group. Fig. $2 \mathrm{~B}$ shows the hydroxyproline (Hyp) concentration results. A significantly lower Hyp concentration was found in all SrR groups compared with the control group at days 7 and 14, which indicated the protective effect of SrR against collagen degradation. Fig. 2C and D shows the relative gene expression of aggrecan and Col-II. Significantly higher expression of aggrecan and Col-II was found in the SrR groups than in the control groups and higher concentrations of SrR resulted in an improved trend. Fig. 2E-G presents the gene expression of $\beta$-catenin, MMP-9 and MMP-13 and SrR significantly suppressed gene expression.

Effects of SrR on chondrocyte Col-II, aggrecan, $\beta$-catenin, MMP-9 and MMP-13 protein synthesis. The chondrocytes were treated with $0,0.125,0.25$ and $0.50 \mathrm{mmol} / 1 \mathrm{SrR}$ for
14 days, which was followed by immunofluorescence staining to visualize the location and concentration of $\beta$-catenin, Col-II and MMP-13 protein. The results showed a clear dose-dependent effect of SrR on promoting chondrocyte function. $\beta$-catenin was highly expressed and located inside the nucleus in the control group, while SrR treatment resulted in lighter staining and a significantly lower expression of $\beta$-catenin in the $0.50 \mathrm{mmol} / 1$ treatment group (Fig. 3A) compared to that of the control. The same situation could be seen in Fig. 3C: MMP-13 was positively stained in cytoplasm around the nucleus and its expression was lower in the higher concentration group. Col-II located in cytoplasm and extracellular area and had the opposite expression trend: the control group had the lowest expression and a higher concentration of SrR resulted in higher expression (Fig. 3B). Fig. 3D presents the WB results, which provided a clearer view of the relative quantified protein content. There was an increasing amount of Col-II and aggrecan in the SrR groups and $\beta$-catenin, MMP-13 and MMP-9 were decreased in the SrR groups at higher concentrations (Fig. 3E).

Effects of SrR on IL-1 $\beta$-inflamed chondrocyte gene and protein expression. To understand whether SrR has an anti-inflammatory effect, $10 \mathrm{ng} / \mathrm{l} \mathrm{IL-1} \beta$ was applied to chondrocyte culture medium and the cells treated with or without SrR for 3 days. Toluidine blue chondrocytes staining showed a significant inhibitory effect of IL-1 $\beta$ on PG synthesis and SrR reversed this effect (Fig. 4A). Fig. 4B, D and E shows that the relative gene expression of $\beta$-catenin, MMP-13 and MMP-9 had similar tendencies. IL-1 $\beta$ could significantly promote the expression of MMPs and activate $\beta$-catenin. SrR could partially offset this activation. Fig. $4 \mathrm{C}$ shows that IL-1 $\beta$ also depressed Col-II gene expression and that SrR slightly increased Col-II expression but was still significantly lower than that of the control. Fig. 4F shows the western blotting analysis of Col-II, $\beta$-catenin, MMP-13 and MMP-9. The results were consistent with the PCR assay results showing that Col-II was expressed at lower levels in the IL-1 $\beta$ group, but it was clear that $\beta$-catenin, MMP-9 and MMP-13 were highly expressed and SrR reversed these trends (Fig 4G).

Effects of SrR on IL-1 $\beta$-inflamed chondrocyte $\beta$-catenin, Col-II and MMP-13 protein synthesis. The chondrocytes were treated with IL-1 $\beta$ and 0 or $0.50 \mathrm{mmol} / 1 \mathrm{SrR}$ for 3 days, followed by immunofluorescence staining. As shown in Fig. 5A, $\beta$-catenin had a strong stain and accumulated inside the nucleus in the IL-1 $\beta$ group and SrR treatment resulted in slightly shallower staining, but the staining was still darker compared with the control. Col-II was light colored in the IL-1 $\beta$ group but gained a darker stain after being treated with SrR (Fig. 5B). MMP-13 had a remarkably stronger stain in the IL-1 $\beta$ group and SrR could lower its expression (Fig. 5C).

\section{Discussion}

SrR, a classic anti-osteoporosis drug, has been gradually recognized to have an anti-osteoarthritis effect and the scope of its clinical application has gradually expanded in recent years. The role of SrR in promoting osteogenesis (18,24-26), chondrogenesis $(14,15,18,27)$ and angiogenesis $(21,28)$ has been experimentally confirmed, but its anti-inflammatory 


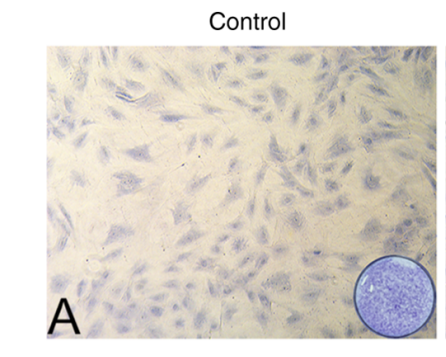

B
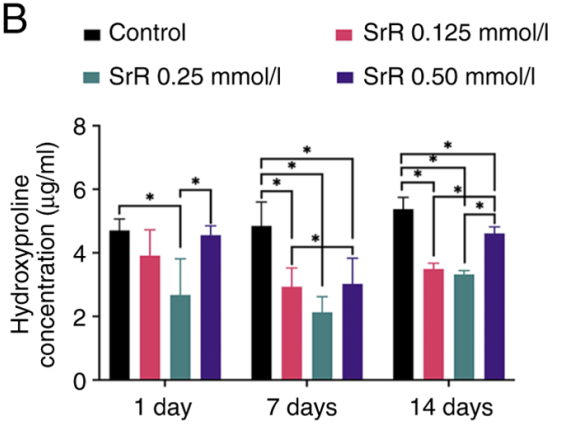

E
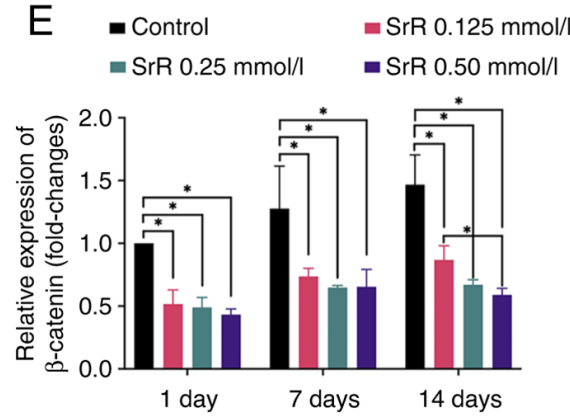

SrR $0.125 \mathrm{mmol} / \mathrm{l}$

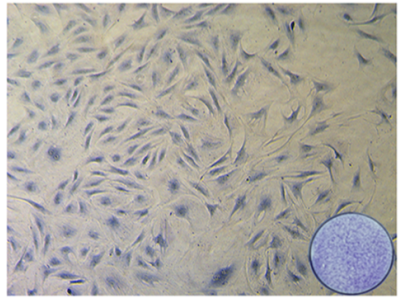

C = Control SrR $0.25 \mathrm{mmol} / \mathrm{l}$
SrR $0.25 \mathrm{mmol} / \mathrm{l}$

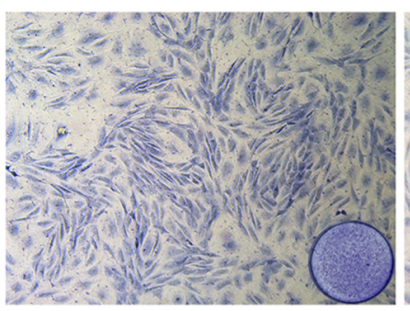

SrR $0.50 \mathrm{mmol} /$

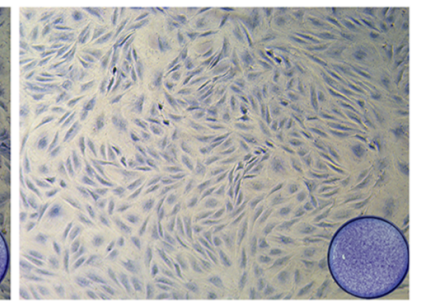

- $\operatorname{SrR} 0.125 \mathrm{mmol} / \mathrm{l}$

- SrR $0.50 \mathrm{mmol} / \mathrm{l}$
D

- Control

- SrR $0.125 \mathrm{mmol} / \mathrm{l}$

$=\mathrm{SrR} 0.25 \mathrm{mmol} / \mathrm{l} \quad=\mathrm{SrR} 0.50 \mathrm{mmol} / \mathrm{l}$
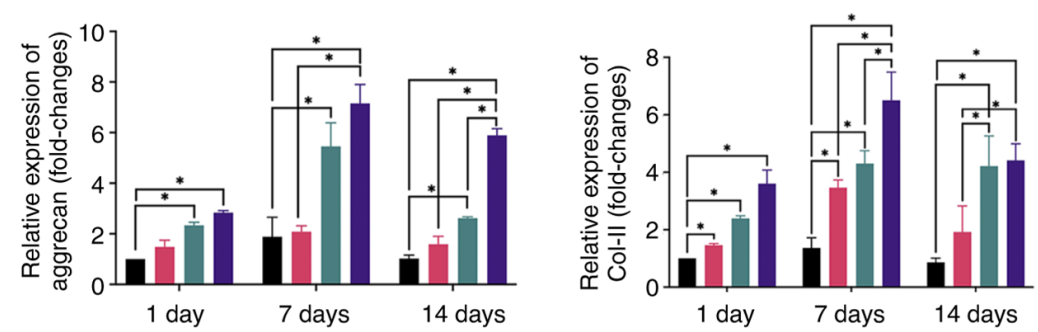

$\mathrm{F}$ - Control = SrR $0.25 \mathrm{mmol} / \mathrm{I}$

- SrR $0.125 \mathrm{mmol} / \mathrm{l}$ - SrR $0.50 \mathrm{mmol} / \mathrm{l}$
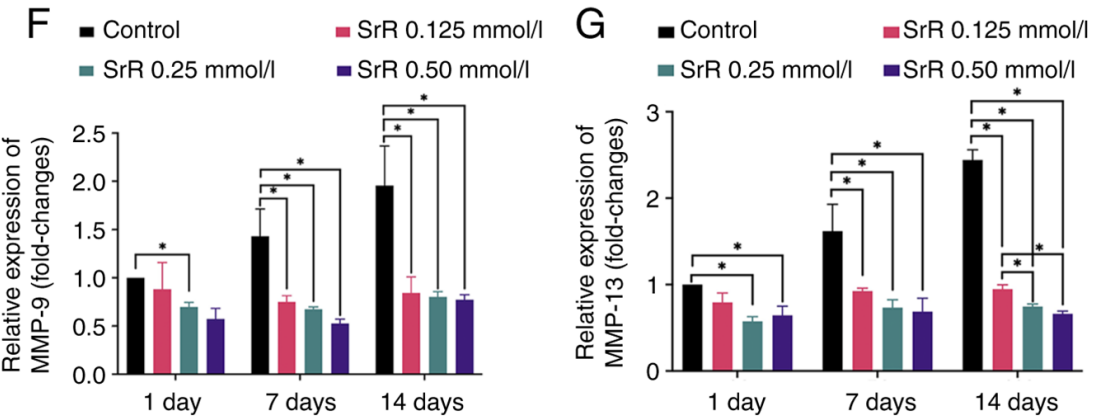

Figure 2. Toluidine blue staining. (A) Hyp concentration and (B) relative gene expression. Relative gene expression of (C) aggrecan, (D) Col-II, (E) $\beta$-catenin, (F) MMP-9 (G) and MMP-13 of rat chondrocytes treated with different concentrations of SrR. The images of $2 \mathrm{~A}$ were captured under x200 magnification. "P<0.05. Hyp, hydroxyproline; Col, collagen; SrR, strontium ranelate.

effect remains to be elucidated. The results demonstrated the anti-inflammatory effect of SrR and evidenced a possible role for the $\mathrm{Wnt} / \beta$-catenin pathway.

Cartilage tissue is composed of cartilage ECM, which mostly contains Col type II and PG, with 15-22 and 4-7\% of the cartilage wet weight, respectively (29) and chondrocytes are the only cell component (3). Cartilage degradation is directly reflected in the increased expression of inflammatory factors represented by the MMP family in chondrocytes (30) and the reduction in ECM protein synthesis, such as Col-II, PG and aggrecan (31). In the study of the anti-inflammatory and cartilage stabilizing effects of drugs, Col-II and PG were used as indicators of cartilage synthesis function and MMPs were key indicators of inflammation levels. The results of the present study showed that SrR could significantly promote the synthesis and secretion of Col-II, PG and aggrecan and inhibit the expression of MMP-9 and MMP-13 inflammatory factors, which means that $\mathrm{SrR}$ can promote cartilage synthesis and inhibit cartilage degradation. So is the result of Hyp test, which is a marker of collagen degradation, that SrR exhibited a protective effect in a normal environment. These results are consistent with previous studies, Tat et al (13) treated subchondral osteoblasts or OA patients with SrR and found that SrR could downregulate the mRNA transcription levels of MMP-2 and MMP-9 and upregulate the expression levels of osteoprotegerin (OPG) and RANK-Ligand (RANKL) to inhibit bone resorption. Similarly, Pelletier et al (32) demonstrated that SrR can also downregulate the expression levels of MMP-1, MMP-13 and cathepsin K, which play an anti-OA role. In addition, Yu et al (14) showed that SrR could also increase the synthesis of type II collagen and chondroproteoglycan by upregulating Sox-9, a marker protein of cartilage differentiation, to weaken subchondral bone remodeling, improve local bone microstructure and alleviate articular cartilage degeneration and poor subchondral bone remodeling (33-35).

At present, researchers define $\mathrm{SrR}$ as a possible DMOAD due to its stabilizing subchondral bone resorption $(11,36)$. Rodrigues et al (36) noted in a systematic review that, at present, there is only moderate clinical evidence to confirm the positive effect of SrR on OA treatment, especially its anti-inflammatory effect, which needs to be confirmed by more studies. The results of the present study clearly demonstrated the role of $\mathrm{SrR}$ in protecting chondrocytes in an environment containing the inflammatory factor IL-1 $\beta$. IL-1 $\beta$ has been proven to be a direct pathogenic factor of OA and can trigger the synthesis of MMPs such as MMP-1, 3, 9 and 13, resulting in cartilage damage $(9,10)$. Chondrocytes in an environment with a high level of IL-1 $\beta$ showed a significant reduction in PG and Col-II synthesis and ECM degradation and a significant increase in MMP-9 and MMP-13, while SrR partially reversed 

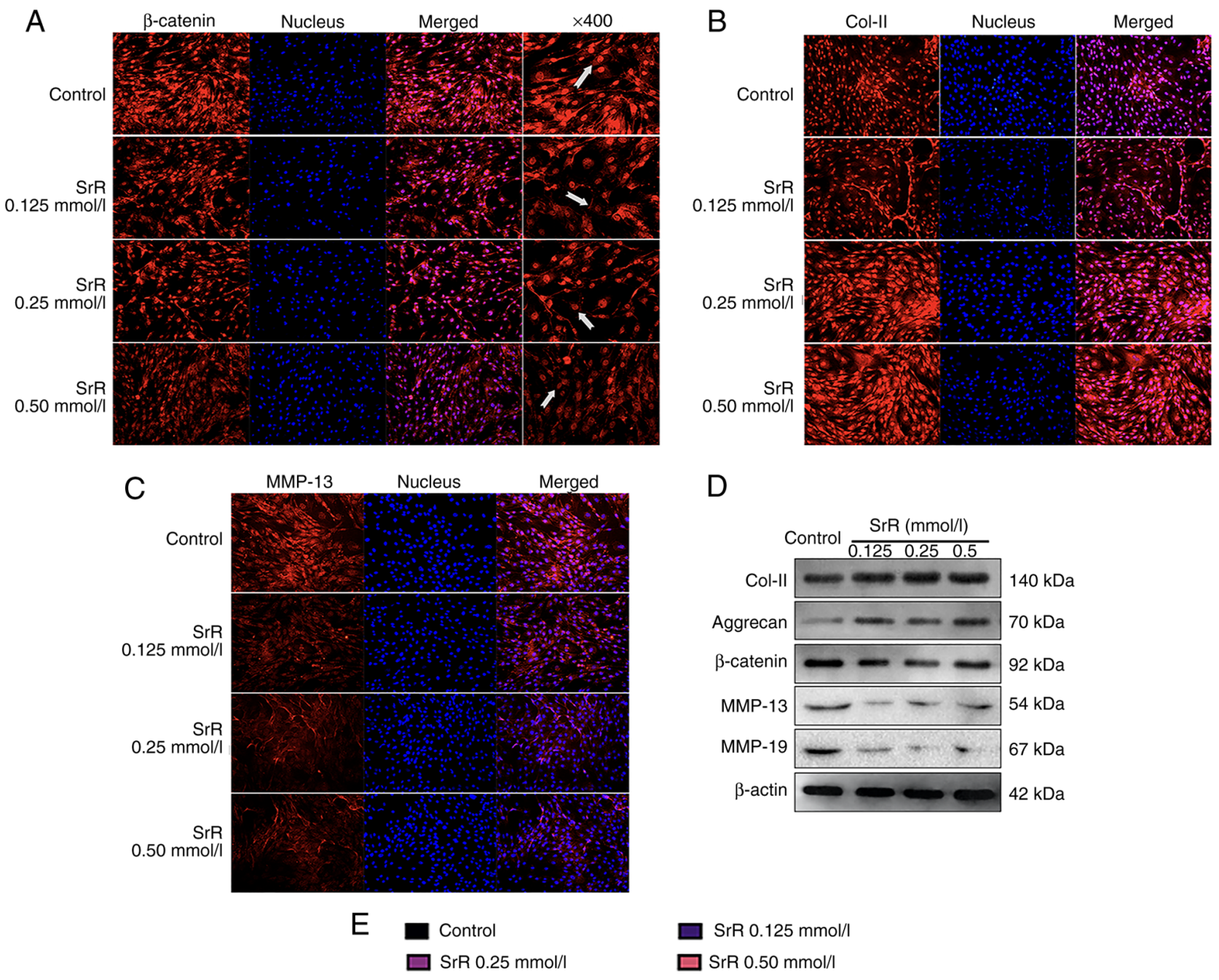
SrR $0.125 \mathrm{mmol} / \mathrm{l}$
SrR $0.50 \mathrm{mmol} / \mathrm{l}$
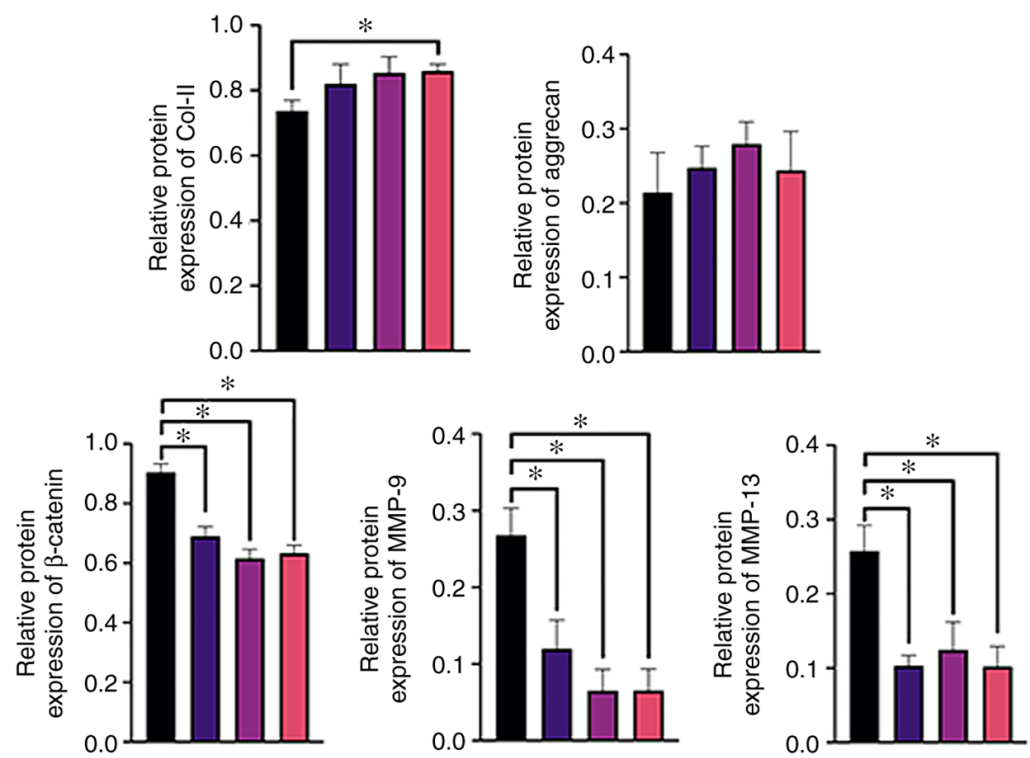

Figure 3. Immunofluorescence staining assay of (A) $\beta$-catenin, (B) Col-II and (C) MMP-13. (D) Western blot assay of Col-II, aggrecan, $\beta$-catenin, MMP-13, MMP-9 and $\beta$-actin and (E) relative protein expression. The images were captured under x 200 magnification, save for the right hand column of (A). Arrows indicate the position of $\beta$-catenin. " $\mathrm{P}<0.05$ as indicated. Col, collagen.

this trend (Figs. 4 and 5). Henrotin et al (18) employed chondrocytes from healthy humans and OA patients (relatively high IL-1 $\beta$ expression) and treated them with SrR. The results also showed strongly stimulated PG and insulin-like growth factor I synthesis, improved cartilage matrix synthesis and effective inhibition of MMPs. These results suggest that SrR has an anti-inflammatory effect at least at the chondrocyte level. 
A

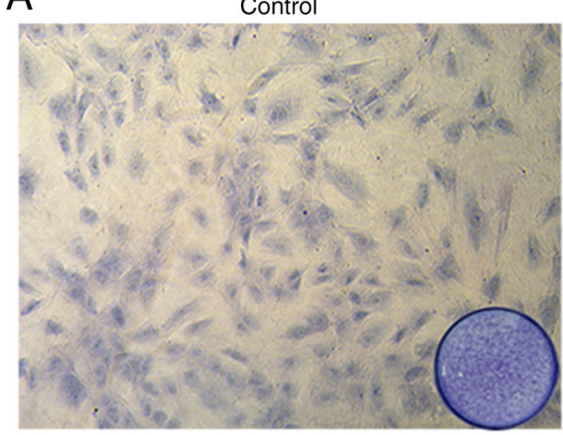

B

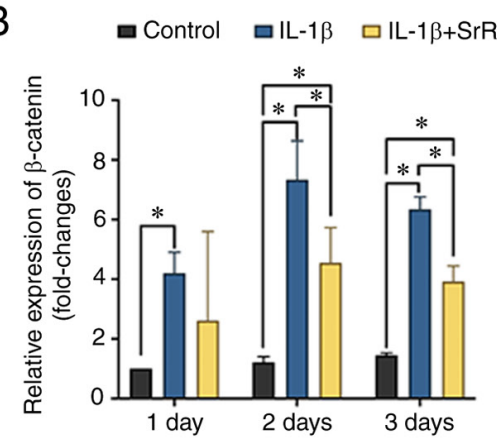

$\mathrm{IL}-1 \beta$

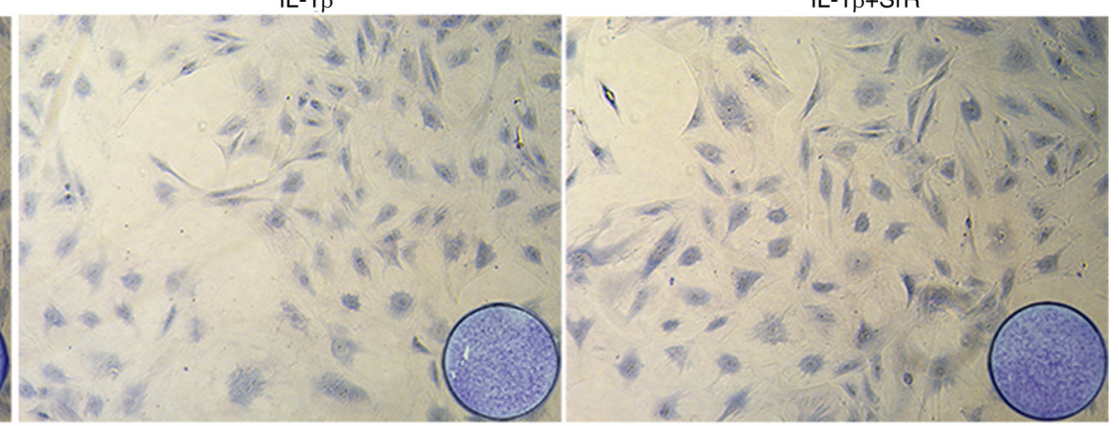

C $\square$ Control $\square$ IL-1 $1 \beta \quad \square I L-1 \beta+S r R$

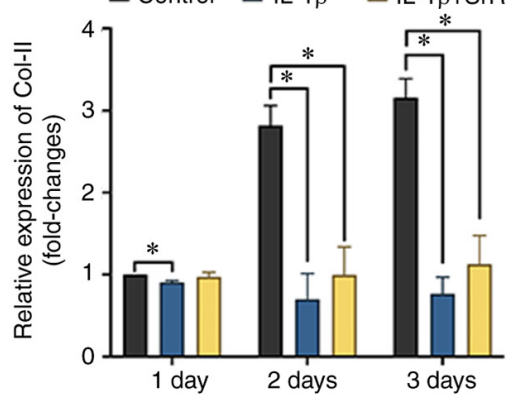

D $\square$ Control $\square \mathrm{IL}-1 \beta \quad \square \mathrm{IL}-1 \beta+\mathrm{SrR}$

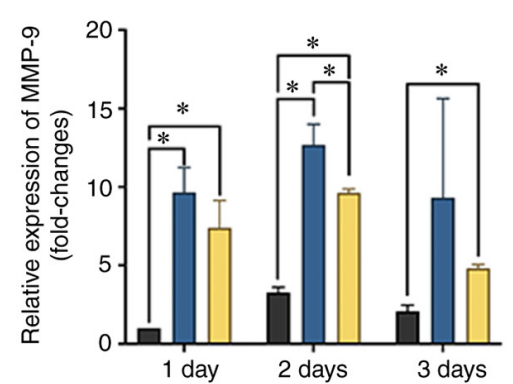

E

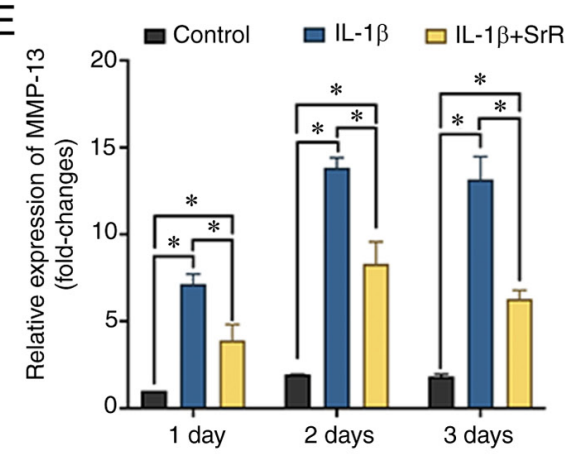

F

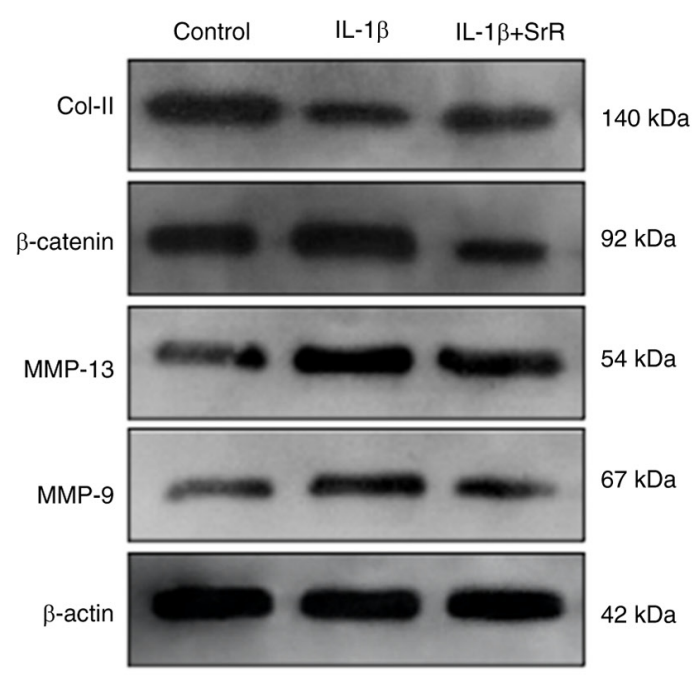

G

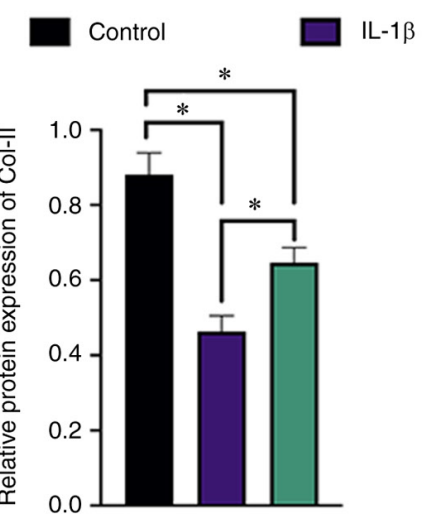

$-1 \beta$

$\mathrm{IL}-1 \beta+\mathrm{SrR}$
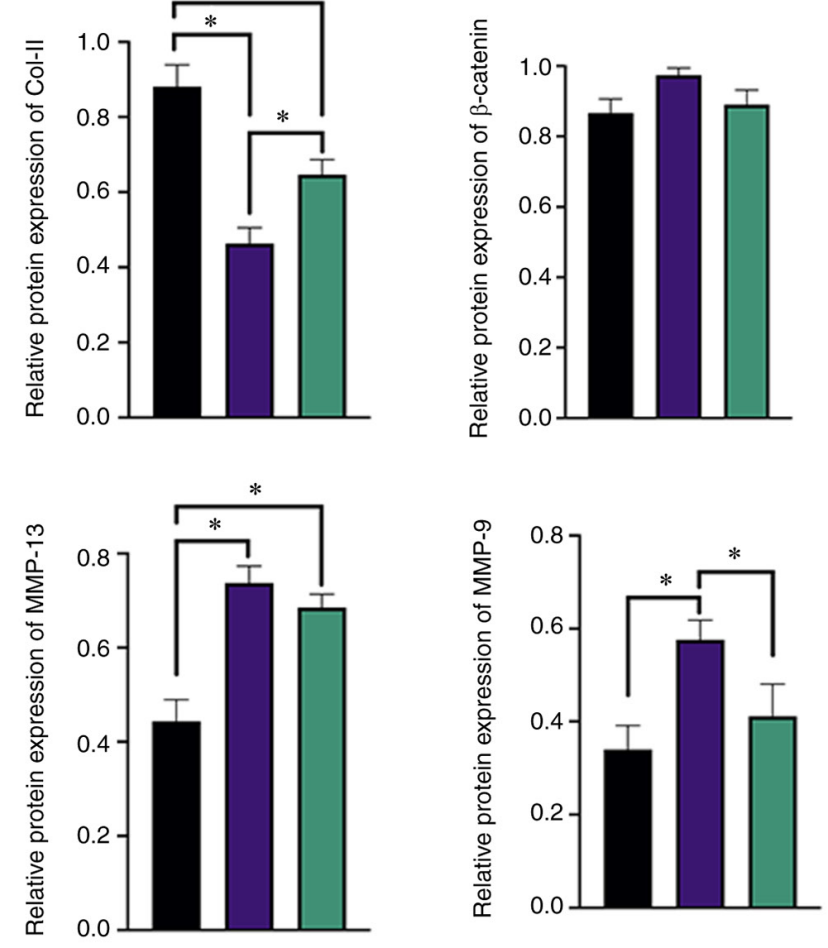

Figure 4. Chondrocytes respond to IL-1 $\beta$ and SrR. (A) Toluidine blue staining and (B), relative gene expression of $\beta$-catenin. Relative gene expression of (C) Col-II, (D) MMP-9 and (E) MMP-13. (F) Western blotting analysis and (G) relative protein expression of chondrocytes treated with 10 ng/1 IL-1 $\beta$ and 0 or $0.50 \mathrm{mmol} / 1 \mathrm{SrR}$ for three days. The images were captured under x 200 magnification. * $\mathrm{P}<0.05$. Col, collagen; SrR, strontium ranelate; $\mathrm{d}$, day.

The present study investigated whether the Wnt $/ \beta$-catenin pathway, especially $\beta$-catenin, was involved in the anti-inflammatory effect of $\mathrm{SrR}$. The Wnt/ $\beta$-catenin pathway serves a crucial role in chondrocyte proliferation, differentiation and apoptosis (37) and aggravates OA by promoting MMPs (38). Wnt/ $\beta$-catenin signaling in human chondrocytes has an unexpected anticatabolic role by counteracting NF- $\mathrm{KB}$-mediated MMP expression induced by IL- $1 \beta$ in a negative feedback loop (39). A previous study has shown that in animals, IL-1 $\beta$ indirectly activates 

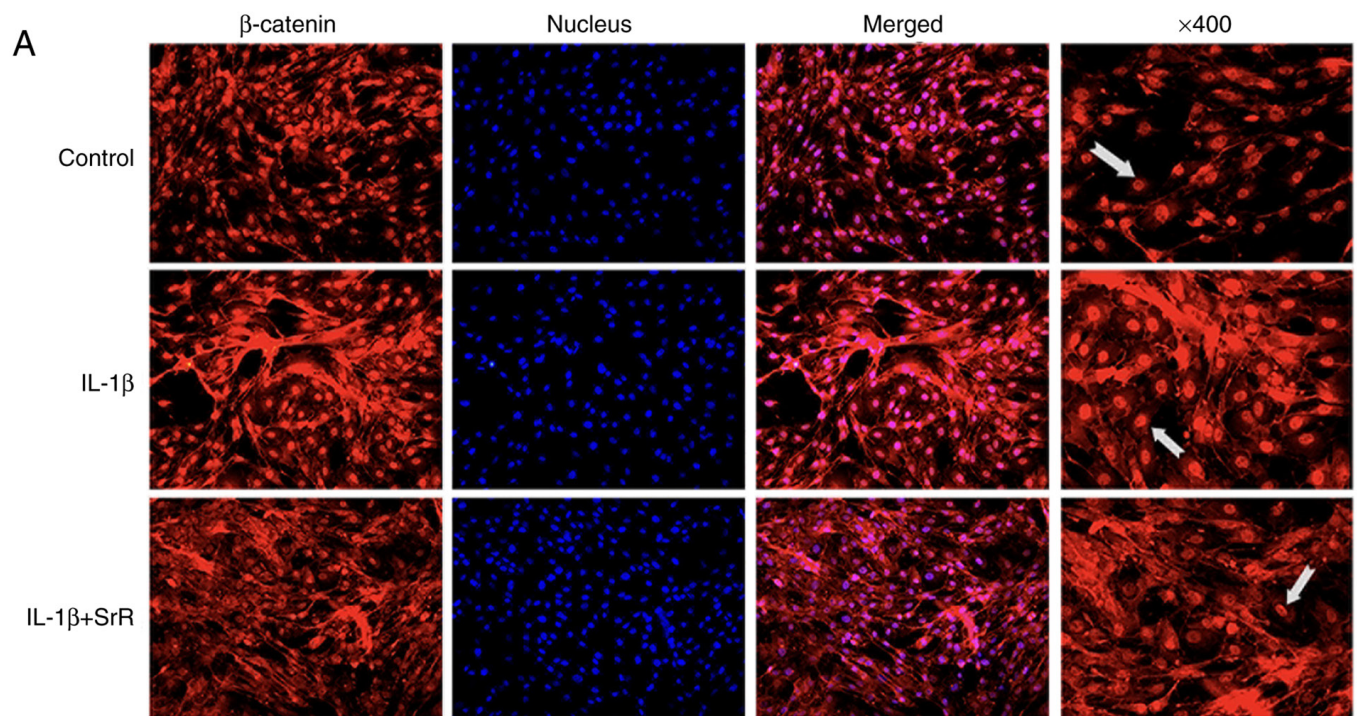

B
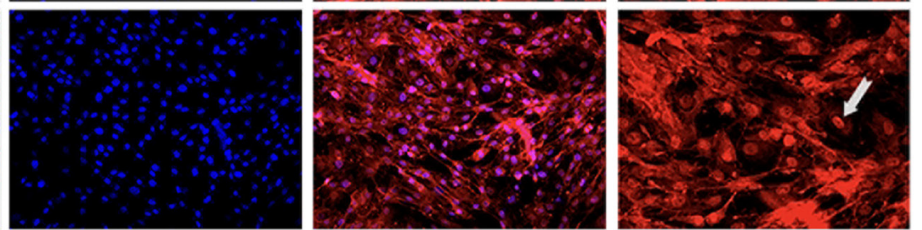

Coll-II Nucleus

Merged
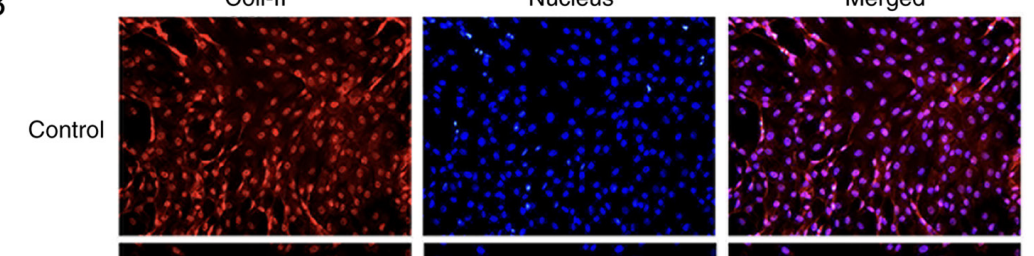

$\mathrm{IL}-1 \beta$
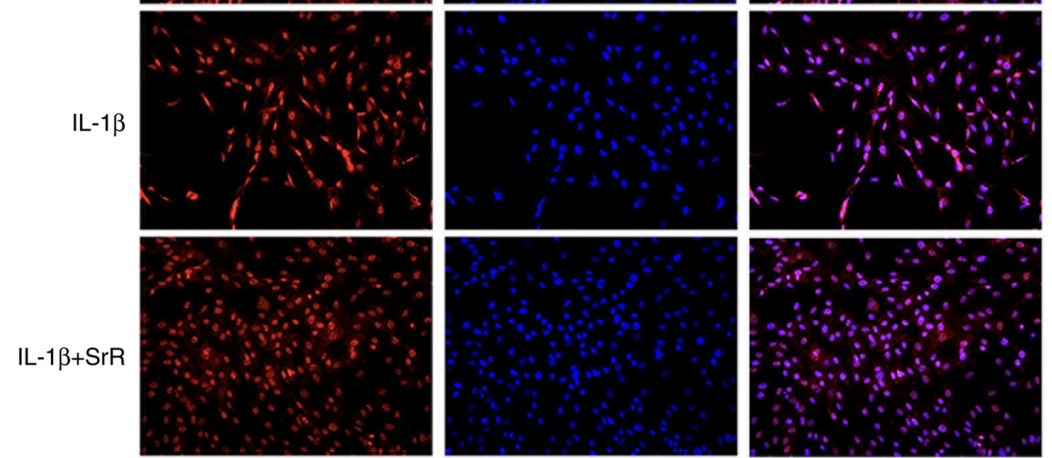

C
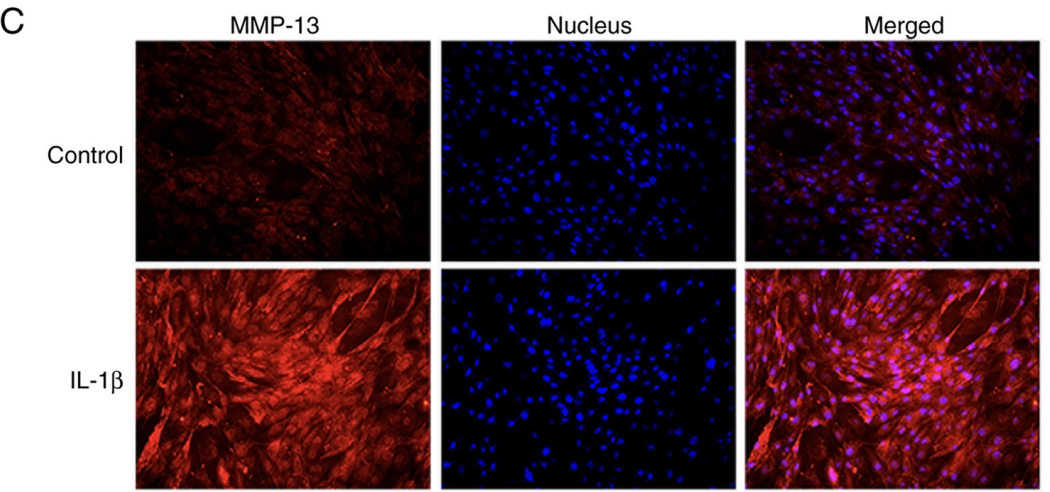

$\mathrm{IL}-1 \beta+\mathrm{SrR}$
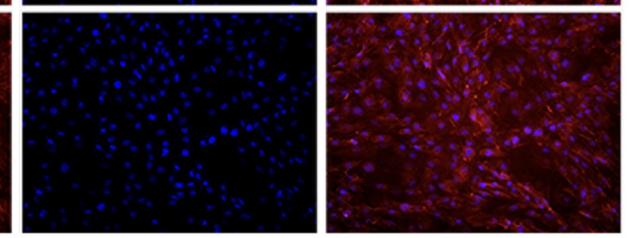

Figure 5. Immunofluorescence staining assay of (A) $\beta$-catenin, (B) Col-II and (C) MMP-13 following three days of induction with IL-1 $\beta$ and SrR. Arrow showed the position of $\beta$-catenin. The images were captured under x200 magnification, save for the right hand column of (A). Arrows indicate the position of $\beta$-catenin. Col, collagen; $\mathrm{SrR}$, strontium ranelate.

canonical Wnt signaling by upregulating Wnt ligands (40). Subsequently, the transcription complex of $\beta$-catenin with
TCF/lEF induces the expression of MMP-3 and MMP-13, leading to cartilage destruction (41). On the other hand, 
activation of the Wnt/ $\beta$-catenin pathway may lead to abnormal osteogenesis but depress chondrogenesis (42). The reciprocal inhibitory effect between $\beta$-catenin and Sox-9 was observed by Akiyama et al (43), in which Sox-9 represses $\beta$-catenin/Tcf/lef complex activities and shows an inhibitory effect on $\beta$-catenin when the cells were in the chondrogenic differentiation trend but a controversial trend when osteogenesis was dominant. The upregulation of $\beta$-catenin led to the inhibition of Col-II and PG synthesis. Taken together, cartilage degradation is correlated to the promotion of $\beta$-catenin activity. The present study showed that SrR could inhibit $\beta$-catenin synthesis and accumulation. In normal chondrocytes, $\beta$-catenin and MMP synthesis decreased with increasing SrR concentration $(\leq 0.50 \mathrm{mmol} / \mathrm{l})$. The addition of IL-1 $\beta$ significantly activated $\beta$-catenin expression and SrR attenuated the increase in $\beta$-catenin induced by IL- $1 \beta$. However, further studies with more bio-markers, including in vivo experiments, are required to further determine the mechanism and confirm the role of $\beta$-catenin in the anti-inflammatory effect of SrR.

SrR has specific characteristics, such as a regular effect on the RANK/RANKL/OPG system that promotes bone formation and inhibits bone resorption (44), increases the vascularization of new bone tissue (21), encourages chondrogenesis in cartilage tissue (35) and reduces the expression of inflammatory factors. All these results made SrR a promising drug for DMOADs. However, more reliable evidence, especially well-designed clinical trials, is needed to confirm the anti-OA effects.

In conclusion, SrR decreased MMPs but promoted Col-II, aggrecan and PG synthesis in rat chondrocytes with or without the presence of IL- $1 \beta$ and SrR attenuated the increase in $\beta$-catenin induced by IL-1 $\beta$, thus reducing the inflammatory reaction.

\section{Acknowledgements}

The authors would like to thank Dr Xinxin Han and Dr Shangfeng Liu (Shanghai Key Laboratory of Craniomaxillofacial Development and Diseases, Fudan University, Shanghai, China), and Mr. Xiaolong Feng and Mr. Longyu Li (Shanghai Research Centre of Model Organisms, Shanghai, China) for the assistance and execution of the experiments.

\section{Funding}

The authors acknowledge the financial support from the Shanghai Commission of Science and Technology (grant no. 19YF1442400).

\section{Availability of data and materials}

The datasets used and/or analyzed during the current study are available from the corresponding author on reasonable request.

\section{Authors' contributions}

HY performed most of the cell molecular biological tests. YL and XY helped HY with the primary chondrocytes cell isolation and culture. JH performed the statistical analysis. QZ was responsible for the study design and revised the manuscript.
XG performed the study design, statistical analysis and wrote the manuscript. XG and QZ confirm the authenticity of all the raw data. All authors read and approved the final manuscript.

\section{Ethics approval and consent to participant}

All experiments involving animals were approved by the Animal Research Committee of the Shanghai Stomatological Hospital and Shanghai Research Center of Model Animal Organization (IACUC No. 2020-0010-06).

\section{Patient consent for publication}

Not applicable.

\section{Competing interests}

The authors declare that they have no competing interests.

\section{References}

1. Joseph R, Rahena A, Hassan N, Glen H, James W and Soichiro I: Epidemiology of temporomandibular disorder in the general population: A systematic review. Adv Dent Oral Health 10: 555787, 2019.

2. Wang XD, Zhang JN, Gan YH and Zhou YH: Current understanding of pathogenesis and treatment of TMJ osteoarthritis. J Dent Res 94: 666-673, 2015.

3. Charlier E, Deroyer C, Ciregia F, Malaise O, Neuville S, Plener Z, Malaise $M$ and de Seny D: Chondrocyte dedifferentiation and osteoarthritis (OA). Biochem Pharmacol 165: 49-65, 2019.

4. Wojdasiewicz P, Poniatowski ŁA and Szukiewicz D: The role of inflammatory and anti-inflammatory cytokines in the pathogenesis of osteoarthritis. Mediators Inflamm 2014: 561459, 2014.

5. Loeser RF: Molecular mechanisms of cartilage destruction: Mechanics, inflammatory mediators, and aging collide. Arthritis Rheum 54: 1357-1360, 2006.

6. Johnson CI, Argyle DJ and Clements DN: In vitro models for the study of osteoarthritis. Vet J 209: 40-49, 2016.

7. Samavedi S, Diaz-Rodriguez P, Erndt-Marino JD and Hahn MS: A three-dimensional chondrocyte-macrophage coculture system to probe inflammation in experimental osteoarthritis. Tissue Eng Part A 23: 101-114, 2017.

8. Gu YT, Chen J, Meng ZL, Ge WY, Bian YY, Cheng SW, Xing CK Yao JL, Fu J and Peng L: Research progress on osteoarthritis treatment mechanisms. Biomed Pharmacother 93: 1246-1252, 2017.

9. Xia B, Chen D, Zhang J, Hu S, Jin H and Tong P: Osteoarthritis pathogenesis: A review of molecular mechanisms. Calcif Tissue Int 95: 495-505, 2014.

10. Grässel S and Muschter D: Recent advances in the treatment of osteoarthritis. F1000Res 9: 325, 2020.

11. Pelletier JP, Roubille C, Raynauld JP, Abram F, Dorais M, Delorme P and Martel-Pelletier J: Disease-modifying effect of strontium ranelate in a subset of patients from the phase III knee osteoarthritis study SEKOIA using quantitative MRI: Reduction in bone marrow lesions protects against cartilage loss. Ann Rheum Dis 74: 422-429, 2015.

12. Tenti S, Cheleschi S, Guidelli GM, Galeazzi M, Fioravanti A: What about strontium ranelate in osteoarthritis? Doubts and securities. Mod Rheumatol 24: 881-884, 2014.

13. Tat SK, Pelletier JP, Mineau F, Caron J and Martel-Pelletier J: Strontium ranelate inhibits key factors affecting bone remodeling in human osteoarthritic subchondral bone osteoblasts. Bone 49: 559-567, 2011.

14. Yu DG, Ding HF, Mao YQ, Liu M, Yu B, Zhao X, Wang XQ, Li Y, Liu GW, Nie SB, et al: Strontium ranelate reduces cartilage degeneration and subchondral bone remodeling in rat osteoarthritis model. Acta Pharmacol Sin 34: 393-402, 2013.

15. Yu H, Liu Y, Yang X, He J, Zhang F, Zhong Q and Guo X: Strontium ranelate promotes chondrogenesis through inhibition of the Wnt/ $\beta$-catenin pathway. Stem Cell Res Ther 12: 296, 2021. 
16. Sun Y, Zhou L, Lv D, Liu H, He T and Wang X: Poly(ADP-ribose) polymerase 1 inhibition prevents interleukin-1 $\beta$-induced inflammation in human osteoarthritic chondrocytes. Acta Biochim Biophys Sin (Shanghai) 47: 422-430, 2015.

17. Alves SM, Abreu SC, Lemos JC, Gomes FI, Alves SM, do Val DR, Freitas RS, Pereira KM, de Paulo Teixeira Pinto V, de Castro Brito GA, et al: Anti-inflammatory and anti-nociceptive effects of strontium ranelate on the zymosan-induced temporomandibular joint inflammatory hypernociception in rats depend on TNF- $\alpha$ inhibition. Pharmacol Rep 69: 764-772, 2017.

18. Henrotin Y, Labasse A, Zheng SX, Galais P, Tsouderos Y, Crielaard JM and Reginster JY: Strontium ranelate increases cartilage matrix formation. Bone Miner Res 16: 299-308, 2001.

19. Wang L, Lazebnik M and Detamore MS: Hyaline cartilage cells outperform mandibular condylar cartilage cells in a TMJ fibrocartilage tissue engineering application. Osteoarthritis Cartilage 17: 346-353, 2009.

20. National Research Council. Guide for the care and use of laboratory animals: Eighth edition. Washington, DC: The National Academies Press, 2011. https://doi.org/10.17226/12910.

21. Guo X, Wei S, Lu M, Shao Z, Lu J, Xia L, Lin K and Zou D: Dose-dependent effects of strontium ranelate on ovariectomy rat bone marrow mesenchymal stem cells and human umbilical vein endothelial cells. Int J Biol Sci 12: 1511-1522, 2016.

22. da Silva CM, Spinelli E and Rodrigues SV: Fast and sensitive collagen quantification by alkaline hydrolysis/hydroxyproline assay. Food Chem 173: 619-623, 2015.

23. Livak KJ and Schmittgen TD: Analysis of relative gene expression data using real-time quantitative PCR and the 2(-Delta Delta C(T)) method. Methods 25: 402-408, 2001

24. Aimaiti A, Maimaitiyiming A, Boyong X, Aji K, Li C and Cui L: Low-dose strontium stimulates osteogenesis but high-dose doses cause apoptosis in human adipose-derived stem cells via regulation of the ERK1/2 signaling pathway. Stem Cell Res Ther 8: 282, 2017.

25. Mao Z, Fang Z, Yang Y, Chen X, Wang Y, Kang J, Qu X, Yuan W and Dai K: Strontium ranelate-loaded PLGA porous microspheres enhancing the osteogenesis of MC3T3-E1 cells. RSC Adv 7: 24607-24615, 2017.

26. Pilmane M, Salma-Ancane K, Loca D, Locs J and BerzinaCimdina L: Strontium and strontium ranelate: Historical review of some of their functions. Mater Sci Eng C Mater Biol Appl 78: 1222-1230, 2017.

27. Deepthi S, Abdul Gafoor AA, Sivashanmugam A, Nair SV and Jayakumar R: Nanostrontium ranelate incorporated injectable hydrogel enhanced matrix production supporting chondrogenesis in vitro. J Mater Chem B 4: 4092-4103, 2016

28. Pan FY, Li ZM, Liu XW, Luo Y, Ma Z, Feng SX and Xu N: Effect of strontium ranelate on rabbits with steroid-induced osteonecrosis of femoral head through TGF- $\beta 1 /$ BMP2 pathway. Eur Rev Med Pharmacol Sci 24: 1000-1006, 2020.

29. Jackson A and Gu W: Transport properties of cartilaginous tissues. Curr Rheumatol Rev 5: 40, 2009.

30. Troeberg L and Nagase H: Proteases involved in cartilage matrix degradation in osteoarthritis. Biochim Biophys Acta 1824: $133-145,2012$

31. Liu-Bryan R and Terkeltaub R: Emerging regulators of the inflammatory process in osteoarthritis. Nat Rev Rheumatol 11: $35-44,2015$.
32. Pelletier JP, Kapoor M, Fahmi H, Lajeunesse D, Blesius A, Maillet J and Martel-Pelletier J: Strontium ranelate reduces the progression of experimental dog osteoarthritis by inhibiting the expression of key proteases in cartilage and of IL- $1 \beta$ in the synovium. Ann Rheum Dis 72: 250-257, 2013.

33. Lefebvre V, Behringer RR and de Crombrugghe B: L-Sox5, Sox6 and Sox 9 control essential steps of the chondrocyte differentiation pathway. Osteoarthritis Cartilage 9 (Suppl A): S69-S75, 2001.

34. Oh CD, Lu Y, Liang S, Mori-Akiyama Y, Chen D, de Crombrugghe B and Yasuda H: SOX9 regulates multiple genes in chondrocytes, including genes encoding ECM proteins, ECM modification enzymes, receptors and transporters. PLoS One 9: e107577, 2014.

35. Kim HJ and Im GI: Electroporation-mediated transfer of SOX trio genes (SOX-5, SOX-6, and SOX-9) to enhance the chondrogenesis of mesenchymal stem cells. Stem Cells Dev 20: 2103-2114, 2011.

36. Rodrigues TA, Freire AO, Bonfim BF, Cartágenes MS and Garcia JB: Strontium ranelate as a possible disease-modifying osteoarthritis drug: A systematic review. Braz J Med Biol Res 51: e7440, 2018.

37. Sassi N, Laadhar L, Allouche M, Achek A, Kallel-Sellami M, Makni S and Sellami S: WNT signaling and chondrocytes: From cell fate determination to osteoarthritis physiopathology. J Recept Signal Transduct Res 34: 73-80, 2014.

38. Xia H, Cao D, Yang F, Yang W, Li W, Liu P, Wang S and Yang F: Jiawei Yanghe decoction ameliorates cartilage degradation in vitro and vivo via $\mathrm{Wnt} / \beta$-catenin signaling pathway. Biomed Pharmacother 122: 109708, 2020.

39. Ma B, van Blitterswijk CA and Karperien M: A Wnt/ $\beta$-catenin negative feedback loop inhibits interleukin-1-induced matrix metalloproteinase expression in human articular chondrocytes. Arthritis Rheum 64: 2589-2600, 2012.

40. Yoshida Y, Yamasaki S, Oi K, Kuranobu T, Nojima T, Miyaki S, Ida $\mathrm{H}$ and Sugiyama E: IL-1 $\beta$ enhances Wnt signal by inhibiting DKK1. Inflammation 41: 1945-1954, 2018.

41. Yun K and Im SH: Transcriptional regulation of MMP13 by Lef1 in chondrocytes. Biochem Biophys Res Commun 364: 1009-1014, 2007.

42. Zhu M, Tang D, Wu Q, Hao S, Chen M, Xie C, Rosier RN, O'Keefe RJ, Zuscik M and Chen D: Activation of beta-catenin signaling in articular chondrocytes leads to osteoarthritis-like phenotype in adult beta-catenin conditional activation mice. J Bone Miner Res 24: 12-21, 2009.

43. Akiyama H, Lyons JP, Mori-Akiyama Y, Yang X, Zhang R, Zhang Z, Deng JM, Taketo MM, Nakamura T, Behringer RR, et al: Interactions between Sox9 and beta-catenin control chondrocyte differentiation. Genes Dev 18: 1072-1087, 2004.

44. Han W, Fan S, Bai X and Ding C: Strontium ranelate, a promising disease modifying osteoarthritis drug. Expert Opin Investig Drugs 26: 375-380, 2017.

This work is licensed under a Creative Commons Attribution-NonCommercial-NoDerivatives 4.0 International (CC BY-NC-ND 4.0) License. 